\title{
A Push-to-Talk Application as an Inter-Professional Communication Tool in an Emergency Department During the COVID-19 Pandemic
}

\author{
Osama Kentab' \\ Khaled Soliman (D)' \\ Ahmad AAl Ibrahim' \\ Abdulaziz Alresseeni' \\ Khalid Aljohani' \\ Muna Aljahany (D) ${ }^{2}$ \\ 'Emergency Department, King Abdullah \\ Bin Abdulaziz University Hospital, \\ Princess Nourah Bint Abdulrahman \\ University, Riyadh, Saudi Arabia; ${ }^{2}$ Clinical \\ Sciences Department, College of \\ Medicine, Princess Nourah Bint \\ Abdulrahman University, Riyadh, Saudi \\ Arabia
}

Objective: To assess the effects of using a smartphone-based push-to-talk (PTT) application on communication, safety, and clinical performance of emergency department (ED) workers during the COVID-19 outbreak.

Design: An observational, cross-sectional study.

Setting: ED in an academic medical center.

Participants: All ED staff members, including physicians (consultants, specialists, residents, and interns), nurses, emergency medical services staff, technicians (X-ray), and administration employees.

Interventions: Eligible participants $(\mathrm{n}=128)$ were invited to fill out an online questionnaire 30 days after using a PTT application for sharing instant voice messages during the COVID19 outbreak.

Main Outcome Measures: Self-reported data related to communication, implementation of personal protective measures, and clinical performance at the ED were collected and analyzed on a 5-item Likert scale (from 5 [strongly agree] to 1 [strongly disagree]). Also, the proportions of favorable responses (agree or strongly agree) were calculated.

Results: Responses of 119 participants (51.3\% females, 58.8\% nurses, and $34.5 \%$ physicians; $90.4 \%$ received at least one notification per day) were analyzed. The participants had favorable responses regarding all domains of communication (between $63.0 \%$ and $81.5 \%$ ), taking precautionary infection control measures (between $49.6 \%$ and $79.0 \%$ ), and performance (between 55.5\% and 72.3\%). Receiving fake and annoying alerts and application breakdowns were the lowest perceived limitations (between $12.5 \%$ and $21.0 \%$ ).

Conclusion: The assessed PTT application can be generalized to other departments and hospitals dealing with patients with COVID-19 to optimize staff safety and institutional preparedness.

Keywords: communication, emergency department, pandemic, COVID-19

\section{Introduction}

The novel coronavirus (SARS-CoV-2) is highly contagious. It is mainly transmitted via respiratory droplets as a result of sneezing or coughing, or close contact with patients or carriers. ${ }^{1}$ Aerosol transmission is also possible in closed spaces. ${ }^{2}$ Symptomatic patients are likely the main source of virus transmission. However, the resulting disease (COVID-19) has an asymptomatic ratio estimated between $17.9 \%$ and $41.6 \% .{ }^{3,4}$ Although disease transmissibility of asymptomatic cases is still unclear, the patterns of spread of the novel virus along with its high
Correspondence: Ahmad AAl Ibrahim Tel +966590262612

Email AMAllbrahim@kaauh.edu.sa; 
asymptomatic ratio emphasize the need to meticulously assess each patient presenting with symptoms mimicking those of COVID-19.

In a significant proportion of patients, the disease is characterized by symptoms resembling those of mild common cold, such as low-grade fever, body aches, sore throat, and dry cough. ${ }^{5}$ A subset of patients would be presented to Emergency Departments (EDs) due to worsening of their clinical manifestations as a result of pneumonia, which might be complicated by acute respiratory distress syndrome. Indeed, in the era of pandemics, such as COVID-19, EDs play a pivotal role in patient triage and initial management. However, there are high chances of contracting occupational COVID-19 infection among healthcare workers (HCWs), particularly when patients' diagnosis is not yet confirmed. ${ }^{6} \mathrm{HCWs}$ represented $29 \%$ of all cases reviewed in a case series of 138 patients in China. $^{7}$ Of the infected $\mathrm{HCWs}, 17.5 \%$ were working in ED. ${ }^{7}$ Therefore, it is imperative to ensure adequate emergency preparedness, triage processes, and the use of protective equipment by ED staff.

Because of distinct and unique challenges in EDs, where overcrowding in unrestricted-access areas is evident on a 24-hour basis, it is crucial to implement an effective inter-professional communication and take infection control measures. Communicative disruption in EDs may become more significant with the opening of new isolation areas, which are remote from EDs. Cases presenting with respiratory symptoms at the ED of King Abdullah bin Abdulaziz University Hospital (KAAUH), Riyadh, Saudi Arabia, are received by a triage nurse to categorize patients according to their clinical conditions. The respiratory zone was about 25 meters away from main ED entrance. Staff used to communicate either personally, leaving their designated areas, or through calls using phone extensions which is frequently left unanswered. The lack of instant communication between nurses and other healthcare professionals had led to disruption in notifying other staff members while transferring patients with respiratory manifestations, particularly those with unstable conditions, to the designated area of resuscitation. Confounded with the criticality of the case and the urge of wearing personal protective equipment (PPE) properly, nurses were subject to make errors that might have led to improper donning and doffing practices, which might have breached safety measures.

As such, there was a need to improve communication via instant messaging among ED staff to take the relevant precautionary infection control measures upon receiving a suspected patient. An efficient alarm system relies on rapid, secure, and non-disruptive tools. Instant messaging through mobile phone applications may provide promising solutions for healthcare professionals. ${ }^{89}$ Instant voice messages sent via push-to-talk (PTT) applications installed on smartphones offer network-based rapid alarm systems that facilitate communication. PTT applications provide instant connectivity as there is no need to dial specific numbers to contact others. They also provide real-time group contact, and most of them are affordable (free of charge or cheap).

For these purposes, the use of a voice messaging PTT application was mandated at KAAUH- ED during the COVID-19 outbreak. Concomitantly, no previous studies have demonstrated the benefits/limitations of using PTT applications in EDs during disastrous periods. In the present study, we sought to assess the self-reported perceptions of ED staff regarding the impact of the new alarm system on inter-professional communication, use of infection control measures, ED preparedness, and clinical performance while providing care to patients suspected with COVID-19.

\section{Methods \\ Study Design and Population}

The ED staff working at KAAUH used a new alarm system involving the use of a PTT application on their smartphones. A cross-sectional, descriptive study was conducted among them after 30 days of implementing the new alarm system. KAAUH belongs to the Princess Norah bint Abdulrahman University campus, and the ED of the hospital has 150 working staff members. The study protocol was approved by the Institutional Review Board of the Princess Norah bint Abdulrahman University. All staff members working in different shifts were invited to participate voluntarily while at work. These included physicians (consultants, specialists, residents, and interns), nurses, ambulance staff, technicians (X-ray), and administration employees. In addition, the excluded staff were those having a chronic disease (hypertension, diabetes, etc.) since they had been granted a provisional leave during the COVID-19 pandemic. Ultimately, there were 128 eligible participants. Participants' data were kept highly confidential and used solely for research purposes. No patients were involved in the current research. 


\section{The Use of the PTT Application at the ED}

The PTT application (Zello 4.96.3 PTT Walkie Talkie, Zello Inc) was used to create a specific channel used as a radio platform for information sharing and communication among ED staff. Instant voice messages sent via the PTT application installed on smartphones offered a rapid alarm systems that facilitate direct and clear communications. All doctors and nurses were added to the channel, and they were trained to use the application without sharing personal data, such as patients' names and medical record numbers. The personal smartphones were packed in specimen bags in a clean area before entering the respiratory zone to limit their contamination. All staff were instructed to share notifications and emergency information about the patients upon presentation, such as the triage category and the respiratory severity score. Registration officers were also added to the same channel to register patients' data into the ED system after receiving information over their smartphones. All hospital staff subscribed to the PTT channel were regularly notified about patients referred for admission in internal wards or intensive care units, such that they could get prepared and equipped with PPE.

\section{Data Collection Tool}

The study tool was a comprehensive structured questionnaire developed based on a systematic literature review of studies concerning the impacts of electronic communication methods on the quality of the care provided in healthcare institutions. ${ }^{10-13}$ Such studies were primarily concerned with the impact of internet-based communication methods, such as e-mails and message sharing applications, on the quality of inter-professional communication. In general, the questionnaire included seven major domains and 43 items: 1) sociodemographic characteristics ( 8 items): age, nationality, gender, marital status, etc.; 2) aspects of using the PTT application (7 items): the currently preferred methods of interprofessional communication, the previous experience of using the PTT application, the average number of notifications received daily, etc.; 3 ) the effects of communication (9 items): the perceived improvements in physician and non-physician response times, the speed and reliability of internal communication, etc.; 4) the perceived effects on taking infection control measures ( 3 items), including the changes in time needed to wear PPE and patient care as well as the perceived changes in staff safety due to exposure to infection; 5) effects on performance (3 items), including preparedness, patient assessment, and the overall performance; 6) job-related stress (5 items), including the changes in restfulness, discouragement, comfort at the workplace, and worries about acquiring the COVID-19 infection; and 7) the perceived limitations of the application (7 items), including receiving fake alerts, annoyance, network interruptions, technical difficulties, etc. The responses to items allocated to domains 3-7 were provided on a 5 -item Likert grade, ranging from 5 (strongly agree) to 1 (strongly disagree).

\section{Data Collection Technique}

The questionnaire was uploaded to the SurveyMonkey ${ }^{\circledR}$ platform (www.surveymonkey.com), which allows creating a special weblink for customized questionnaires. Staff members provided their responses through their smartphones or any other electronic device, where each participant could provide his/her answers only once. We downloaded all responses upon reaching the target size of eligible participants $(n=128)$, and checked the dataset for missing data using Microsoft Excel (version 2016).

\section{Statistical Analysis}

The database was exported to and coded in Statistical Package for Social Sciences software version 26 (SPSS Inc., Chicago, IL, USA). The reliability of different items was assessed by calculating Cronbach's alpha coefficient. Qualitative sociodemographic variables and those representing the aspects of PTT use were expressed as frequencies, percentages, and their respective $95 \%$ confidence intervals (95\% CIs). For Likert grade responses (ordinal data), data were presented as medians and interquartile ranges (IQRs). ${ }^{14}$ The responses at Likert grades of 4 and 5 (agree and strongly agree, respectively) were regarded as favorable, whereas the responses at Likert grades of 1 (strongly disagree), 2 (disagree), or 3 (neutral responses) were regarded as unfavorable. To further obtain reliable outcomes from the reported responses, we used the sign test to investigate the null hypothesis stating that the median response equals 3 (neutral) on the Likert grading system for each item of domains 3-7.

Percentage scores were calculated for distinct domains that represented the primary outcomes. Minimum and maximum raw scores of communication ( 9 and 45, respectively), changes in the preventive measures (3 and 15, respectively), and performance (7 and 35 , respectively) were converted to their respective percentage values for 
easy interpretation. This was carried out using the following formula: $(S * 100) / M$, where $S$ indicates the sum of items in each domain and $\mathrm{M}$ indicates the maximum score. The obtained data were tested for normality using the Kolmogorov-Smirnov and Shapiro-Wilk tests. The $\mathrm{p}$ values of such tests were $<0.05$ for all domains, indicating non-normally distributed data. Statistical comparisons of percentage scores were performed using the MannWhitney $U$-test for binomial variables or Kruskal-Wallis test for multinomial variables. A $p$ value of $<0.05$ indicated significant differences.

\section{Ethical Approval}

The study protocol was approved by the Institutional Review Board of the Princess Norah bint Abdulrahman University. Moreover, participants provided informed consent before participation.

\section{Results}

\section{The Internal Consistency of the}

\section{Questionnaire}

The Cronbach's alpha value for all items of the questionnaire was 0.85 , indicating very good reliability. For subscale analyses, alpha values for the effects of PTT on ED practice were 0.90 for communication (nine items), 0.79 for the risk of infection (three items), and 0.86 for the overall performance in EDs (four items).

\section{Characteristics of the Respondents}

Of the total 128 responses, 9 were excluded because they lacked the primary outcomes. Therefore, responses of 119 participants underwent further analyses. Of these participants, $63.0 \%$ were aged $\leq 35$ years, $51.3 \%$ were females, $74.8 \%$ were non-Saudis, $52.1 \%$ were married, and $57.1 \%$ had a Bachelor's degree. Nurses represented more than half of the participants $(58.8 \%)$, followed by physicians $(34.5 \%)$; and most of them $(97.5 \%)$ were in direct contact with patients at the ED (Table 1).

\section{Aspects of Using the PTT Application}

More than half of the respondents had used all the available methods of communication at the ED (58.5\%); 56.8\% of participants had a previous experience of using the application. Most of the respondents (90.4\%) received at least one notification per day, and the response was perceived as immediate (from 0 to 1 minute) by $45.7 \%$ of participants and from 1 to 5 minutes by $43.1 \%$ of
Table I Sociodemographic and Occupational Characteristics of the Participants $(n=119)$

\begin{tabular}{|c|c|c|c|}
\hline Parameter & Category & Frequency & $\begin{array}{l}\text { Percentage } \\
(95 \% \mathrm{Cl})\end{array}$ \\
\hline \multirow[t]{5}{*}{ Age (years) } & $\leq 35$ & 75 & 63 (54.4-71.7) \\
\hline & $36-45$ & 32 & $26.9(18.9-34.9)$ \\
\hline & $46-55$ & 8 & $6.7(2.2-11.2)$ \\
\hline & $56-65$ & 2 & I.7 (0-4) \\
\hline & $>65$ & 2 & I.7 (0-4) \\
\hline \multirow[t]{2}{*}{ Nationality } & Saudi & 30 & $25.2(17.4-33)$ \\
\hline & Non-Saudi & 89 & $74.8(67-82.6)$ \\
\hline \multirow[t]{2}{*}{ Gender } & Male & 58 & 48.7 (39.8-57.7) \\
\hline & Female & 61 & $51.3(42.3-60.2)$ \\
\hline \multirow[t]{3}{*}{ Marital status } & Married & 62 & 52.1 (43.I-6I.I) \\
\hline & Never married & 53 & $44.5(35.6-53.5)$ \\
\hline & Divorced & 4 & $3.4(0.1-6.6)$ \\
\hline \multirow[t]{4}{*}{ Education level } & Bachelor & 68 & $57.1(48.3-66)$ \\
\hline & Diploma & 5 & $4.2(0.6-7.8)$ \\
\hline & Master/PhD & 19 & $16(9.4-22.5)$ \\
\hline & $\begin{array}{l}\text { Board certified/ } \\
\text { fellowship }\end{array}$ & 27 & $22.7(15.2-30.2)$ \\
\hline \multirow{5}{*}{$\begin{array}{l}\text { Occupation } \\
\text { group }\end{array}$} & Doctor & 41 & $34.5(25.9-43)$ \\
\hline & Nurse & 70 & $58.8(50-67.7)$ \\
\hline & Technicians & 3 & $2.5(0-5.3)$ \\
\hline & Registration officers & 1 & $0.8(0-2.5)$ \\
\hline & Other & 4 & $3.4(0.1-6.6)$ \\
\hline \multirow[t]{3}{*}{ Practicing } & $\mathrm{I}-5$ years & 24 & $20.2(13-27.4)$ \\
\hline & $5-10$ years & 59 & $49.6(40.6-58.6)$ \\
\hline & $>10$ years & 36 & $30.3(22-38.5)$ \\
\hline \multirow{2}{*}{$\begin{array}{l}\text { Direct patient } \\
\text { contact }\end{array}$} & No & 3 & $2.5(0-5.3)$ \\
\hline & Yes & 116 & $97.5(94.7-100.3)$ \\
\hline
\end{tabular}

participants. The application was easy to use as indicated by $86.5 \%$ of the respondents (Table 2 ).

\section{Effects on Communication, Infection Control Measures, and Job-Related Stress}

After 30 days of using the PTT application, ED staff reported general improvements in all domains of communication and taking precautionary measures during the epidemic within the department (Table 3). Based on the results of the sign tests, all $\mathrm{p}$ values for comparisons were $<0.0001$, and all the median responses were higher than the neutral response (Likert 3 ). In essence, significant proportions of participants indicated that instant voice messages reduced the efforts made to communicate (Likert 4 [IQR 4, 5], 81.5\%), improved the access to healthcare professionals in the ED (Likert 4 [IQR 4, 5], 79.0\%), improved physicians' and non-physicians' response times to urgent COVID-19 reporting (Likert 4 [IQR 4, 5], 
Table 2 Aspects of Using the PTT Application

\begin{tabular}{|c|c|c|c|}
\hline Parameter & Category & Frequency & $\begin{array}{l}\text { Percentage }(95 \% \\
\mathrm{Cl})\end{array}$ \\
\hline $\begin{array}{l}\text { How are you most likely to communicate with } \\
\text { other ED staff members? }\end{array}$ & $\begin{array}{l}\text { Face-to-face only } \\
\text { Telephone only } \\
\text { Face-to-face, telephone, email, and other } \\
\text { methods except the PTT application } \\
\text { PTT application only } \\
\text { All methods } \\
\text { Missing }\end{array}$ & $\begin{array}{l}11 \\
2 \\
29 \\
7 \\
69 \\
1\end{array}$ & $\begin{array}{l}9.2(4-14.4) \\
1.7(0-4) \\
24.4(16.7-32.1) \\
5.9(1.7-10.1) \\
58(49.1-66.9) \\
0.8(0-2.5)\end{array}$ \\
\hline Previous experience with the PTT application & $\begin{array}{l}\text { No } \\
\text { Yes } \\
\text { Missing }\end{array}$ & $\begin{array}{l}51 \\
67 \\
1\end{array}$ & $\begin{array}{l}42.9(34-51.7) \\
56.3(47.4-65.2) \\
0.8(0-2.5)\end{array}$ \\
\hline When did you start using the PTT application? & $\begin{array}{l}\text { Just started in the COVID-19 era } \\
\text { Less than I year ago } \\
\text { One year ago or more } \\
\text { Missing }\end{array}$ & $\begin{array}{l}92 \\
20 \\
5 \\
2\end{array}$ & $\begin{array}{l}77.3(69.8-84.8) \\
16.8(10.1-23.5) \\
4.2(0.6-7.8) \\
1.7(0-4)\end{array}$ \\
\hline $\begin{array}{l}\text { The use of the PTT application for other } \\
\text { purposes rather than COVID-19-related alerts }\end{array}$ & $\begin{array}{l}\text { No } \\
\text { Yes } \\
\text { Missing }\end{array}$ & $\begin{array}{l}65 \\
53 \\
1\end{array}$ & $\begin{array}{l}54.6(45.7-63.6) \\
44.5(35.6-53.5) \\
0.8(0-2.5)\end{array}$ \\
\hline $\begin{array}{l}\text { The average number of notifications received in } \\
\text { the PTT application }\end{array}$ & $\begin{array}{l}\text { Zero } \\
\text { I to } 3 \text { times } \\
4 \text { to } 5 \text { times } \\
>5 \text { times } \\
\text { Missing }\end{array}$ & $\begin{array}{l}11 \\
41 \\
22 \\
41 \\
4\end{array}$ & $\begin{array}{l}9.2(4-14.4) \\
34.5(25.9-43) \\
18.5(11.5-25.5) \\
34.5(25.9-43) \\
3.4(0.1-6.6)\end{array}$ \\
\hline $\begin{array}{l}\text { The average length of time it takes for staff to } \\
\text { respond to an alert }\end{array}$ & $\begin{array}{l}\text { I receive no response } \\
0 \text { to I minutes } \\
\text { I to } 5 \text { minutes } \\
5 \text { to } 10 \text { minutes } \\
\text { Longer than } 10 \text { minutes } \\
\text { Missing }\end{array}$ & $\begin{array}{l}8 \\
53 \\
50 \\
3 \\
2 \\
3\end{array}$ & $\begin{array}{l}6.7(2.2-11.2) \\
44.5(35.6-53.5) \\
42(33.1-50.9) \\
2.5(0-5.3) \\
1.7(0-4) \\
2.5(0-5.3)\end{array}$ \\
\hline The application is easy to use & $\begin{array}{l}\text { Strongly Disagree } \\
\text { Disagree } \\
\text { Neither agree nor disagree } \\
\text { Agree } \\
\text { Strongly Agree } \\
\text { Missing }\end{array}$ & $\begin{array}{l}0 \\
4 \\
12 \\
54 \\
48 \\
1\end{array}$ & $\begin{array}{l}0 \\
3.4(0.1-6.6) \\
10.1(4.7-15.5) \\
45.4(36.4-54.3) \\
40.3(31.5-49.2) \\
0.8(0-2.5)\end{array}$ \\
\hline
\end{tabular}

79.0\% and 4 [IQR 3, 4], 74.0\% respectively), and improved the speed of internal communication (Likert 4 [IQR 4, 5], $76.5 \%$ ). However, the majority reported that interprofessional communication still needs improvements (Likert 4 [IQR 4, 5], 83.2\%). Regarding the impact on precautionary responses, about three-quarters of the participants have had sufficient times to wear their PPE (Likert 4 [IQR 4, 4], 78.99\%), while about half of them declared improvements in safety due to reduced exposure to infection (Likert 4
[IQR 3, 4], 58.82\%). Regarding the job-related stress, personal perceptions showed that application use was associated with more restfulness (Likert 3 [IQR 3, 4]) and comfort (Likert 4 $[\mathrm{IQR} 3,4])$ at the workplace, and it reduced the feelings of discouragement (Likert 4 [IQR 3, 4]). Conversely, the lowest degree of agreement was about the worries of being infected by COVID-19 (Likert 3 [IQR 3, 4], 34.5\%, Table 3). During the same period, no reports of contracting COVID-19 among ED staff. 
Table 3 The Responses of the Participants Regarding the Effects of the PTT Application on Inter-Professional Communication, Precautionary Responses, and Job-Related Stress at the Emergency Department $(n=119)$

\begin{tabular}{|c|c|c|c|c|}
\hline Category & Survey Question & $\begin{array}{l}\text { Response } \\
\text { Median } \\
\text { (IQR)* }\end{array}$ & $\begin{array}{l}\text { Favorable } \\
\text { Response (n, } \\
\%)^{\ddagger}\end{array}$ & $\mathbf{P}^{*}$ \\
\hline \multirow{9}{*}{$\begin{array}{l}\text { Effects on inter- } \\
\text { professional } \\
\text { communication }\end{array}$} & $\begin{array}{l}\text { The speed of internal communication in the department has been } \\
\text { improved. }\end{array}$ & $4(4,5)$ & 91 (76.47) & $<0.0001$ \\
\hline & $\begin{array}{l}\text { The reliability of internal communication in the department has been } \\
\text { improved. }\end{array}$ & $4(3,4)$ & $81(68.07)$ & $<0.0001$ \\
\hline & Less effort is required to communicate. & $4(4,5)$ & $97(81.51)$ & $<0.0001$ \\
\hline & Improved access to ED team & $4(4,5)$ & 94 (78.99) & $<0.0001$ \\
\hline & Improved physician response times to urgent COVID-19 reporting & $4(4,5)$ & $94(78.99)$ & $<0.0001$ \\
\hline & I am less likely to delay contacting a physician. & $4(3,4)$ & $84(70.59)$ & $<0.0001$ \\
\hline & Improved non-physician response times & $4(3,4)$ & $88(73.95)$ & $<0.0001$ \\
\hline & Improved job satisfaction & $4(3,4)$ & $75(63.03)$ & $<0.0001$ \\
\hline & Internal communication still needs further improvements. & $4(4,5)$ & $99(83.19)$ & $<0.0001$ \\
\hline \multirow{3}{*}{$\begin{array}{l}\text { Effects on the } \\
\text { Precautionary } \\
\text { Responses }\end{array}$} & $\begin{array}{l}\text { I have sufficient time to wear the personal protective equipment and to } \\
\text { take other precautionary infection control measures. }\end{array}$ & $4(4,4)$ & 94 (78.99) & $<0.0001$ \\
\hline & Staff safety has been improved due to reduced exposure to infection. & $4(3,4)$ & $70(58.82)$ & $<0.0001$ \\
\hline & $\begin{array}{l}\text { The time required for patient care has been reduced due to promoted } \\
\text { preparedness. }\end{array}$ & $3(3,4)$ & $59(49.58)$ & $<0.0001$ \\
\hline \multirow{5}{*}{$\begin{array}{l}\text { The effects on Job- } \\
\text { related Stress }\end{array}$} & I have become less worried about acquiring the COVID-19 infection & $3(3,4)$ & $4 \mathrm{I}(34.45)$ & 0.065 \\
\hline & I have become more restful. & $3(3,4)$ & $52(43.7)$ & $<0.0001$ \\
\hline & I do not have trouble remembering things. & $4(3,4)$ & $62(52.1)$ & $<0.0001$ \\
\hline & I do not feel discouragedlfrustratedldisappointed. & $4(3,4)$ & $6 \mathrm{I}(5 \mathrm{I} .26)$ & $<0.0001$ \\
\hline & Improved my comfort at the workplace. & $4(3,4)$ & $83(69.75)$ & $<0.0001$ \\
\hline
\end{tabular}

Notes: *All responses were presented on a 5 -point Likert scale, where 5 indicates the highest grade (strongly agree). ${ }^{\ddagger}$ Favorable responses indicate the frequencies of participants with the following responses: agree (Likert grade 4) or strongly agree (Likert grade 5). ${ }^{¥}$ The $p$ value to test the null hypothesis using a sign test (to investigate whether the median response equals 3 [neutral]).

Abbreviations: ED, emergency department; IQR, interquartile range.

\section{Effects on the Performance at the ED}

The highest levels of agreement regarding the impact of the PTT on the performance at the ED was concerning the improvements in preparedness (Likert 4 [IQR 3, 4], 72.3\%), followed by patient assessment time (Likert 4 [IQR 3, 4], $60.5 \%$ ), and the effects on the overall performance (Likert 4 [IQR 3, 4], 55.5\%). The differences between the median of these responses and the neutral response were significant ( $<<0.0001$ for all). Therefore, 94 of the participants $(79.0 \%$, $95 \%$ CI, $71.4 \%$ to $85.7 \%$ ) recommend the use of the PTT application in other non-COVID-19 areas (Figure 1).

\section{The Perceived Limitations of the PTT Application}

Significant low proportions of the participants agreed that they received fake alerts (Likert 2 [IQR 2, 3], $12.6 \%$ ), voice messages were annoying (Likert 3 [IQR 2, 3], 18.5\%), and they experienced delays in real-time notifications (Likert 3 [IQR 2, 3], 21.0\%, Figure 2). The responses regarding other investigated limitations showed no significant differences as compared to the median neutral values. 
(A)

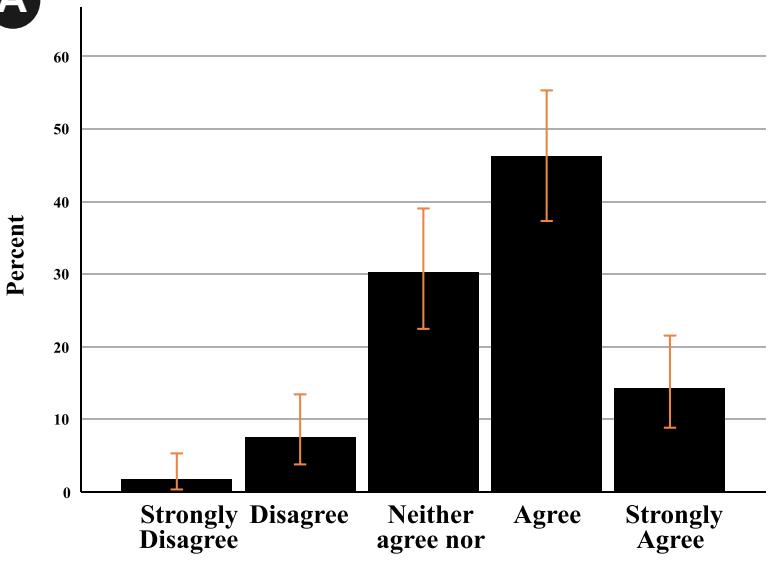

C

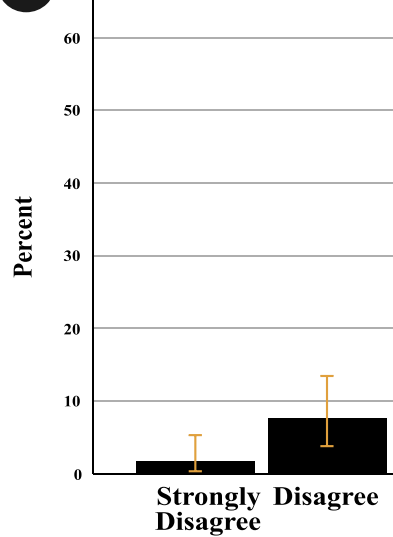

B

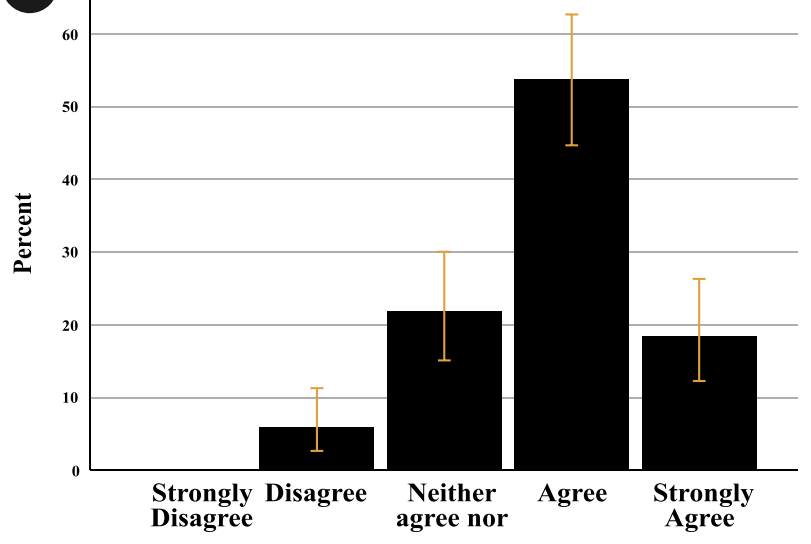

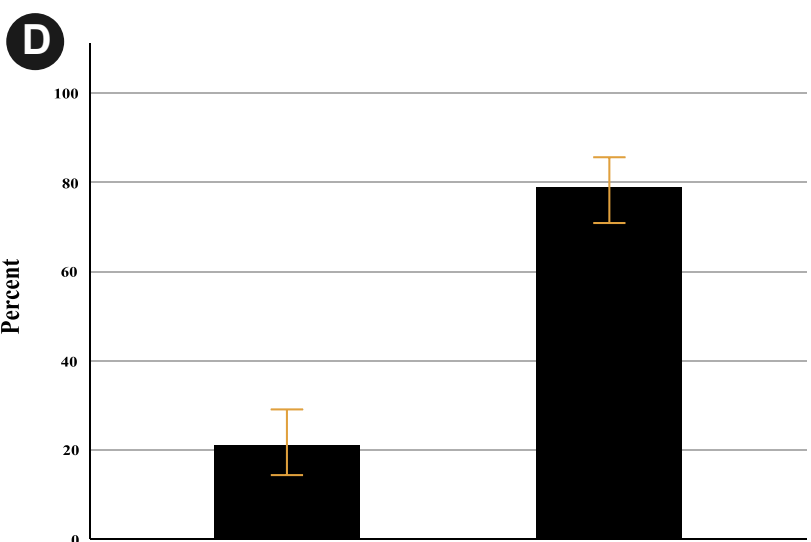

No

Figure I The responses regarding the effects of using the PTT application on participants' performance in EDs and their recommendations regarding its applicability in other nonCOVID-19 areas. Error bars represent the $95 \%$ confidence intervals. (A) The communication system improved the patient assessment time. (B) The communication system improved our preparedness in ED. (C) The communication system had a big impact on my performance. (D) Do you recommend the use of such application in the different areas in ED?.

The application continually breakdown or has significant delays in real-time notification

There are technical difficulties or issues in my smartphone which have influenced alarms received on the PTT application

There are significant interruptions in the network connectivity, which have influenced alarms received on the PTT application

The received alerts have negatively influenced history taking and other aspects of the quality of patient care due to frequent distractions

Voice messages are annoying
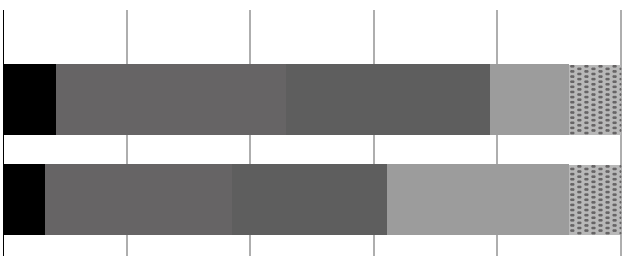

I frequently receive fake alerts

The use of the application requires training


Figure 2 The perceived responses regarding the limitations of the PTT applications. 


\section{Scores of Communication, Changes in} Preventive Infection Control Measures, and ED Performance

For all the participants, the percentage scores of communication, changes in the precautionary measures, and performance were significantly different than those of the neutral responses $(p<0.0001$ for all). Considering pair-wise comparisons based on sociodemographic characteristics, significant differences were found in communication scores based on the occupation group and experience, while performance scores varied based on participants' experience solely. Concerning subgroup analyses, the communication score implied by ED technicians was significantly lower than all other occupational groups $(\mathrm{p}=0.024)$. Interestingly, experienced ED staff (working for $>10$ years) scored higher in the communication $(p=0.016)$ and performance $(p=0.022)$ domains than the less-experienced group (5-10 years). Other comparisons showed no significant differences between different sociodemographic groups in communication, changes in preventive measures, and performance at the ED (Table 4).

Table 4 Percentage Scores of Communication, Changes in Preventive Measures, and Performance

\begin{tabular}{|c|c|c|c|c|c|c|c|c|c|c|}
\hline \multirow[t]{2}{*}{ Parameter } & \multirow[t]{2}{*}{ Category } & \multicolumn{3}{|c|}{ Communication } & \multicolumn{3}{|c|}{ Precautionary Measures } & \multicolumn{3}{|c|}{ Performance } \\
\hline & & Median & IQR & $\mathbf{P} *$ & Median & IQR & $\mathbf{P} *$ & Median & IQR & $\mathbf{P} *$ \\
\hline Whole population & Nil & 80.00 & $71.11-84.4$ & $<0.0001$ & 73.3333 & $66.67-80.00$ & $<0.0001$ & 73.3333 & $60.00-80.00$ & $<0.0001$ \\
\hline Age & $\begin{array}{l}\leq 35 \\
36-45 \\
46-55 \\
56-65 \\
>65\end{array}$ & $\begin{array}{l}80.00 \\
77.78 \\
87.78 \\
83.33 \\
82.22\end{array}$ & $\begin{array}{l}72.78-84.44 \\
67.22-88.89 \\
76.11-95.56 \\
82.22-84.44 \\
80.00-84.44\end{array}$ & 0.373 & $\begin{array}{l}73.33 \\
73.33 \\
73.33 \\
83.33 \\
80.00\end{array}$ & $\begin{array}{l}66.67-80.00 \\
66.67-85.00 \\
56.67-98.33 \\
80.00-86.66 \\
80.00-80.00\end{array}$ & 0.669 & $\begin{array}{l}73.33 \\
80.00 \\
80.00 \\
76.67 \\
80.00\end{array}$ & $\begin{array}{l}60.00-80.00 \\
60.00-80.00 \\
66.67-96.67 \\
73.33-80.01 \\
80.00-80.00\end{array}$ & 0.683 \\
\hline Gender & $\begin{array}{l}\text { Male } \\
\text { Female }\end{array}$ & $\begin{array}{l}80.00 \\
80.00\end{array}$ & $\begin{array}{l}71.11-91.67 \\
73.89-84.44\end{array}$ & 0.538 & $\begin{array}{l}80.00 \\
73.33\end{array}$ & $\begin{array}{l}66.67-80.00 \\
66.67-80.00\end{array}$ & 0.152 & $\begin{array}{l}76.67 \\
73.33\end{array}$ & $\begin{array}{l}60.00-81.67 \\
60.00-80.00\end{array}$ & 0.620 \\
\hline Nationality & $\begin{array}{l}\text { Saudi } \\
\text { Non-Saudi }\end{array}$ & $\begin{array}{l}77.78 \\
80.00\end{array}$ & $\begin{array}{l}71.11-87.22 \\
73.89-84.44\end{array}$ & 0.759 & $\begin{array}{l}73.33 \\
73.33\end{array}$ & $\begin{array}{l}66.67-86.67 \\
66.67-80.00\end{array}$ & 0.686 & $\begin{array}{l}73.33 \\
73.33\end{array}$ & $\begin{array}{l}60-86.67 .00 \\
63.33-80.00\end{array}$ & 0.998 \\
\hline Marital Status & $\begin{array}{l}\text { Married } \\
\text { Never married } \\
\text { Divorced }\end{array}$ & $\begin{array}{l}80.00 \\
80.00 \\
83.33\end{array}$ & $\begin{array}{l}72.78-91.67 \\
69.44-82.22 \\
77.22-86.11\end{array}$ & 0.119 & $\begin{array}{l}80.00 \\
73.33 \\
90.00\end{array}$ & $\begin{array}{l}66.67-83.33 \\
66.67-80.00 \\
61.67-93.33\end{array}$ & 0.166 & $\begin{array}{l}80.00 \\
73.33 \\
86.67\end{array}$ & $\begin{array}{l}60.00-80.00 \\
60.00-80.00 \\
80.00-93.33\end{array}$ & 0.086 \\
\hline Education Level & $\begin{array}{l}\text { Bachelor } \\
\text { Diploma } \\
\text { Master/PhD } \\
\text { Board certified/ } \\
\text { fellowship }\end{array}$ & $\begin{array}{c}80.00 \\
75.56 \\
82.22 \\
80\end{array}$ & $\begin{array}{l}71.11-84.44 \\
62.22-88.89 \\
77.78-91.11 \\
71.11-93.33\end{array}$ & 0.208 & $\begin{array}{l}73.33 \\
73.33 \\
80.00 \\
76.67\end{array}$ & $\begin{array}{l}66.67-80.00 \\
60.00-93.33 \\
66.67-80.00 \\
66.67-88.33\end{array}$ & 0.416 & $\begin{array}{l}73.33 \\
80.00 \\
80.00 \\
73.33\end{array}$ & $\begin{array}{l}60.00-80.00 \\
46.67-83.33 \\
73.33-80.00 \\
60-86.67 .00\end{array}$ & 0.421 \\
\hline Occupation Group & $\begin{array}{l}\text { Doctor } \\
\text { Nurse } \\
\text { Technicians } \\
\text { Registration officers } \\
\text { Others }\end{array}$ & $\begin{array}{l}82.22 \\
80.00 \\
68.89 \\
95.56 \\
86.67\end{array}$ & $\begin{array}{l}72.22-93.33 \\
71.11-82.22 \\
60.00-77.78 \\
95.56-95.56 \\
81.67-88.33\end{array}$ & $0.024^{*}$ & $\begin{array}{c}80 \\
73.33 \\
73.33 \\
100 \\
76.67\end{array}$ & $\begin{array}{l}66.67-86.67 \\
63.33-80.00 \\
53.33-93.33 \\
100-100 \\
73.33-85.00\end{array}$ & 0.088 & $\begin{array}{l}73.33 \\
73.33 \\
33.33 \\
86.67 \\
86.67\end{array}$ & $\begin{array}{l}60.00-83.33 \\
60.00-80.00 \\
26.67-39.99 \\
86.67-86.67 \\
66.67-96.67\end{array}$ & 0.159 \\
\hline Experience & $\begin{array}{l}1 \text { to } 5 \text { years } \\
5 \text { to } 10 \text { years } \\
>10 \text { years }\end{array}$ & $\begin{array}{l}80.00 \\
80.00 \\
82.22\end{array}$ & $\begin{array}{l}71.67-86.11 \\
66.67-82.22 \\
75.56-95.56\end{array}$ & $0.016^{*}$ & $\begin{array}{l}73.33 \\
73.33 \\
76.67\end{array}$ & $\begin{array}{l}66.67-86.67 \\
66.67-80.00 \\
66.67-86.67\end{array}$ & 0.441 & $\begin{array}{l}76.67 \\
73.33 \\
80.00\end{array}$ & $\begin{array}{l}60.00-86.67 \\
60.00-80.00 \\
61.67-86.67\end{array}$ & $0.022^{¥}$ \\
\hline $\begin{array}{l}\text { Direct Patient } \\
\text { Contact }\end{array}$ & $\begin{array}{l}\text { Yes } \\
\text { No }\end{array}$ & $\begin{array}{l}80.00 \\
84.44\end{array}$ & $\begin{array}{l}71.11-84.44 \\
68.89-99.99\end{array}$ & 0.797 & $\begin{array}{l}73.33 \\
80.00\end{array}$ & $\begin{array}{l}66.67-80.00 \\
66.67-93.33\end{array}$ & 0.826 & $\begin{array}{l}73.33 \\
80.00\end{array}$ & $\begin{array}{l}60.00-80.00 \\
26.67-100.00\end{array}$ & 0.743 \\
\hline
\end{tabular}

Notes: *The p values to test the null hypothesis to investigate whether the median percentage response score equals 60 (neutral score) using a sign test for the whole sample; other $\mathrm{P}$ values indicated the difference in ranks of Mann-Whitney U-test for bivariable comparisons or Kruskal-Wallis $H$-test for multivariable comparisons. ¥Indicates significant differences in the calculated scores.

Abbreviation: IQR, interquartile range. 


\section{Discussion}

\section{Principal Findings}

The intradepartmental, inter-professional use of a PTT smartphone application for one month led to significant improvements in communication as perceived by approximately three-quarters of the participants. Additionally, the safety of the staff and the time required to implement preventive measures improved after exchanging the instant voice alarms through the application. These were reflected in clinical performance and preparedness.

\section{Strengths of the Study}

In the present study, we endeavored to define the early perceptions of using an instant messaging application to improve communication within an ED. The novel system ensures quick communication among the staff in the isolation area and those working in the ED in a single press of a button without the need to make phone calls, emails, etc. To the best of our knowledge, we are the first tertiary medical institution to implement such technology and investigate its efficacy as an alarm system. Indeed, the new system can be considered as an integral part of a wider aspect of the local hospital preparedness and the national Infection Prevention and Control program in Saudi Arabia. The isolation area at KAAUH is one of the allocated areas in the Kingdom for isolating patients with COVID-19. Thus, the results of our analysis can widen the applicability of the alarming system to other isolation areas and the concerned hospital departments, such as infectious disease departments, internal medicine, microbiology, and intensive care units.

\section{Findings in Relation to Other Studies}

Traditionally, there were several pitfalls in communication with face-to-face and telephone conversations although they were the most commonly used channels. Communication interruption had previously occurred at significantly higher rates for senior medical and nursing staff than junior staff and registered nurses, particularly during allocated patient loads. ${ }^{15}$ Communication breakdowns account for approximately $70 \%$ of medical errors, which have led to poor patient outcomes. ${ }^{16}$ These errors occur more frequently during crises and emergencies. ${ }^{17}$ However, with the use of the PTT application, our recent findings during the COVID-19 outbreak indicate that various aspects of communication have improved, which include the efforts needed to communicate, improved access to other medical and nonmedical HCWs, and improved responses to notifications. Since patient transfer to the isolation area would take approximately 3-5 minutes, the notified nurses and physicians would have enough time to get prepared and wear PPE. Furthermore, administrative issues would have been resolved since the employees on the same PTT channel would be notified (even while being at home) to intervene immediately, especially when there are no available beds for admission.

Similar to our preparedness plan, communication improvement has been the most frequently applied solution for different challenges in a French hospital during the COVID-19 outbreak. ${ }^{18}$ In particular, regular communicative channels have been adopted between the hospital and ambulatory services to address notifications regarding suspected cases (pre-hospital care), yet no details were provided about the use of distinct communication methods. In our study, we have provided detailed insights into the benefits of the new communication system, which have been well-perceived by the participants within a short period of application (30 days). Moreover, experienced ED staff had significantly more favorable perceptions regarding communication with PTT use, signifying that communication has not been influenced by the highly interactive nature of work of experienced staff members.

Collectively, the used smartphone application showed significant benefits during the outbreak. It has been previously shown that the SMS-based data transmission system installed on smartphones led to significant improvements in the completeness and timeliness of surveillance reports for acute respiratory infections, which could apply to other outbreaks. ${ }^{19}$ The application was used as an alert system to notify other HCWs and signal a potential outbreak. The usability of the application was ranked as $4 / 5$ on all the domains. Similarly, the PTT application in our study has proved to be highly practical by the participating staff (about $79 \%$ of them have just started the application during the COVID-19 outbreak). This may reflect the readiness of HCWs to utilize the new technology for sharing important notifications. This way, the PTT application can be used for additional purposes rather than an alarm system, such as effective hazardous waste management and regular sharing of reliable information regarding the prevention and infection control policies. The latter is of significant concern as infection control policies may be recurrently changing with further improvements in knowledge about the novel virus. ${ }^{20}$ Such applications can be supported by the participants 
recommendations of wider applicability of the new communication system to other non-COVID-19 areas.

However, a significant proportion of the respondents in the present study affirmed that communication needs further improvements. Radiology technicians were the least favorable group regarding the impact of the PTT application on communication. This might partly be explained by their relatively small number $(n=3)$, which might have affected their calculated communication scores. Another possible explanation is that they are involved in indirect patient care; hence, they are more reluctant to communicate with other ED teams and they are less likely to practice the recommended infection control policies. Noncompliance to the use of PPE has been also demonstrated in a cross-sectional survey of ED technicians during the Canadian outbreak of Severe Acute Respiratory Syndrome. ${ }^{21}$ However, technicians working at our department may be approached through specialized interviews to discuss their perceived limitations and the possible ways to promote their integration in the new communication system.

From another perspective, PTT-related limitations may arise in healthcare settings. As with other electronic communication modalities, security violations of the voice message shared on personal smartphones of healthcare practitioners may occur. Although private voice messages are end-to-end encrypted on the used PTT application at our department, shared messages over public channels are prone to privacy and system security violations. ${ }^{22}$ For this reason, ED staff at our department were instructed to avoid sharing patient information via the PTT application. However, the risk of tracking and liability remained apparent. Additionally, despite the use of a specimen bag to cover the smartphones, there is a risk of infection because cell phones might have been contaminated. HCWs should, therefore, be aware of the importance of cleaning their phones along with washing their hands before and after patient care.

\section{Limitations}

The current study has its limitations. First, hindsight bias might have existed, where real-life experience of the interprofessional communication with the application might have impacted participants' judgment compared to the pre-PTT communication. This might have led to an unjustified evaluation of the communicative situation and biased responses. ${ }^{23}$ Second, multiple questions in the survey were phrased positively; thus, the respondents might have been agreeable (acquiesce) to the majority of such items. However, the use of rating choices in survey questions, considering "strongly disagree" as the first option, might have reduced the likelihood of the acquiescence bias. ${ }^{24}$ Third, although the majority of ED staff workers were included, the small number of participants in the survey might lead to a lack of significant differences among different sociodemographic groups. These differences might exist between medical and paramedical occupational groups in the domains of clinical performance and infection control measures. Finally, the inherent limitations of the survey methodology might have contributed to the lack of causal associations. Therefore, future studies should involve multiple ED departments, larger samples, and prospective designs to emphasize the effects of the new system on different infection control domains.

\section{Conclusion}

In conclusion, the use of a PTT application in the ED, KAAUH, Saudi Arabia, was associated with self-reported improvements in all aspects of intradepartmental communication regarding instant notifications of receiving suspected patients with COVID-19. This included reduced efforts to communicate, improved staff responses, and improved access to other staff members. This was reflected in the safety of staff members via reducing the time required to implement infection control protective measures and giving sufficient time to HCWs to wear PPE before the arrival of the suspected patient. In addition, the clinical performance improved owing to improved preparedness and reduced patient assessment time. Future largesized, multidepartmental studies are needed to corroborate the applicability and usability of the promising PTT system.

\section{Funding}

This research was funded by the Deanship of Scientific Research at Princess Nourah Bint Abdulrahman University, Riyadh, Saudi Arabia, through the Fast-track Research Funding Program.

\section{Disclosure}

The authors report no conflicts of interest in this work. 


\section{References}

1. Chan JF-W, Yuan S, Kok K-H, et al. A familial cluster of pneumonia associated with the 2019 novel coronavirus indicating person-toperson transmission: a study of a family cluster. Lancet. 2020;395 (10223):514-523. doi:10.1016/S0140-6736(20)30154-9

2. Guo Y-R, Cao Q-D, Hong Z-S, et al. The origin, transmission and clinical therapies on coronavirus disease 2019 (COVID-19) outbreak: an update on the status. Mil Med Res. 2020;7:1-10. doi:10.1186/ s40779-019-0229-2

3. Nishiura H, Kobayashi T, Miyama T, et al. Estimation of the asymptomatic ratio of novel coronavirus infections (COVID-19) Int J Infect Dis. 2020;94:154-155. doi:10.1016/j.ijid.2020.03.020

4. Mizumoto K, Kagaya K, Zarebski A, et al. Estimating the asymptomatic proportion of coronavirus disease 2019 (COVID-19) cases on board the Diamond Princess cruise ship, Yokohama, Japan, 2020. Euro Surveill. 2020;25:2000180. doi:10.2807/1560-7917. ES.2020.25.10.2000180

5. Siordia JA. Epidemiology and clinical features of COVID-19: a review of current literature. J Clin Virol. 2020;127:104357. doi:10.1016/j.jcv.2020.104357

6. Chavez S, Long B, Koyfman A, et al. Coronavirus disease (COVID-19): a primer for emergency physicians. Am J Emerg Med. 2020. doi:10.1016/j.ajem.2020.03.036

7. Wang D, Hu B, Hu C, et al. Clinical characteristics of 138 hospitalized patients with 2019 novel coronavirus-infected pneumonia in Wuhan, China. JAMA. 2020;323:1061-1069. doi:10.1001/ jama.2020.1585

8. Przybylo JA, Wang A, Loftus P, et al. Smarter hospital communication: secure smartphone text messaging improves provider satisfaction and perception of efficacy, workflow. $J$ Hosp Med. 2014;9:573-578. doi:10.1002/jhm.2228

9. Patel B, Johnston M, Cookson N, et al. Interprofessional communication of clinicians using a mobile phone app: a randomized crossover trial using simulated patients. J Med Internet Res. 2016;18(4):e79-e. doi:10.2196/jmir.4854

10. O'Connor C, Friedrich JO, Scales DC, et al. The use of wireless e-mail to improve healthcare team communication. $J$ Am Med Inform Assoc. 2009;16:705-713. doi:10.1197/jamia.M2299

11. Cooney HJ, Banbury HE, Plunkett AC. Impact of a hands-free wireless communication device on communication and clinical outcomes in a pediatric intensive care. Pediatr Qual Saf. 2018;3:e074-e. doi:10.1097/pq9.0000000000000074

12. Richards JD, Harris T. Beam me up Scotty! Impact of personal wireless communication devices in the emergency department. Emerg Med J. 2011;28:29-32. doi:10.1136/emj.2009.082370
13. Shaarani I, El-Kantar A, Hamzeh N, et al. Interprofessional communication of physicians using whatsapp: physicians' perspective. Telemed $J$ E Health. 2020;26(10):1257-1264. doi:10.1089/ tmj.2019.0216

14. Mircioiu C, Atkinson J. A: comparison of parametric and non-parametric methods applied to a Likert scale. Pharmacy (Basel). 2017;5:26. doi:10.3390/pharmacy5020026

15. Spencer R, Coiera E, Logan P. Variation in communication loads on clinical staff in the emergency department. Ann Emerg Med. 2004;44:268-273. doi:10.1016/j.annemergmed.2004.04.006

16. Calhoun AW, Boone MC, Porter MB, et al. Using simulation to address hierarchy-related errors in medical practice. Perm $J$. 2014;18:14-20. doi:10.7812/TPP/13-124

17. Jung D, Carman M, Aga R, et al. Disaster preparedness in the emergency department using in situ simulation. Adv Emerg Nurs $J$. 2016;38:56-68. doi:10.1097/TME.0000000000000091

18. Peiffer-Smadja N, Lucet J-C, Bendjelloul G, et al. Challenges and issues about organising a hospital to respond to the COVID-19 outbreak: experience from a French reference centre. Clin Microbiol Infect. 2020:S1198-743X(20)30187-7.

19. El-Khatib Z, Shah M, Zallappa SN, et al. SMS-based smartphone application for disease surveillance has doubled completeness and timeliness in a limited-resource setting: evaluation of a 15 -week pilot program in Central African Republic (CAR). Confl Health. 2018;12:42. doi:10.1186/s13031-018-0177-6

20. Mossa-Basha M, Meltzer CC, Kim DC, et al. Radiology department preparedness for COVID-19: radiology scientific expert panel. Radiology. 2020:200988.

21. Visentin LM, Bondy SJ, Schwartz B, et al. Use of personal protective equipment during infectious disease outbreak and nonoutbreak conditions: a survey of emergency medical technicians. Cjem. 2009;11:44-56. doi:10.1017/S1481803500010915

22. Zello.com. Are voice messages encrypted in Zello? United States; 2017 [cited August 18, 2020]. Available from: https://support.zello. com/hc/en-us/articles/230747707-Are-voice-messages-encrypted-inZello-. Accessed May 8, 2021.

23. Banham-Hall E, Stevens S. Hindsight bias critically impacts on clinicians' assessment of care quality in retrospective case note review. Clin Med (Lond). 2019;19:16-21. doi:10.7861/clinmedicine.19-1-16

24. Dunsch F, Evans DK, Macis M, et al. Bias in patient satisfaction surveys: a threat to measuring healthcare quality. BMJ Glob Health. 2018;3:e000694-e. doi:10.1136/bmjgh-2017-000694
Open Access Emergency Medicine

\section{Publish your work in this journal}

The Open Access Emergency Medicine is an international, peerreviewed, open access journal publishing original research, reports, editorials, reviews and commentaries on all aspects of emergency medicine. The manuscript management system is completely online and includes a very quick and fair peer-review system, which is all easy to use. Visit http://www.dovepress.com/testimonials.php to read real quotes from published authors. 